\title{
Tuberculose respiratória: histórico, atualização do diagnóstico e dificuldades do tratamento
}

Desde a história do homem na terra a ciência tem conhecimento das diversas doenças que acometem a espécie humana. Uma dessas doenças é a tuberculose respiratória. O presente trabalho trata-se de uma revisão da literatura de caráter qualitativo, descritivo e exploratório, utilizando como base de pesquisa artigos científicos com no máximo 5 anos de publicação. Também foram utilizados artigos com publicações anteriores a 2011 com dados históricos da doença. A primeira droga utilizada para o tratamento da TB foi estreptomicina e o ácido para-aminosalicílico no ano de 1944. Para o diagnóstico desta enfermidade, são utilizadas várias metodologias do qual, foram sendo atualizadas com o passar do tempo, transitando entre a simples baciloscopia até a atual PCR. Diante das informações abordadas durante todo o trabalho, concluise que, o tratamento da tuberculose em relação aos vários métodos de diagnóstico da doença, apresenta-se sem significantes modificações em sua formulação por um período aproximado de 72 anos.

Palavras-chave: Mal do Século; Mycobacterium tuberculosis; Baciloscopia; Abreugrafia; PCR.

\section{Respiratory tuberculosis: history, update of diagnosis and treatment difficulties}

\begin{abstract}
Ever since the humankind history on the planet, science is aware of the various diseases that attach the humankind and one of them is respiratory tuberculosis. This paper reviews the literature in qualitative, descriptive and exploitative matter, using scientific papers published at 5 years ago at the latest as a basis. Articles published before 2011 with historical data about the disease have also been used. The first medicine used to treat respiratory tuberculosis was streptomycin and para-amino-salicylic acid in 1944. To diagnose this medical condition, many methodologies have been used over time, changing from the simple bacilloscopy to the current PCR. Considering the information covered, we can conclude that the treatment for tuberculosis, in comparison to various diagnose methods of the disease, has not been under many changes in its way for about 72 years.
\end{abstract}

Keywords: Evil of the Century; Mycobacterium tuberculosis; Smear; Abreugraphy; PCR.

Topic: Enfermagem em Doenças Infecciosas

Reviewed anonymously in the process of blind peer

Katrícia Fernanda Ribeiro Venceslau Faculdade Guaraí, Brasil

http://lattes.cnpq.br/8197934197773229

katricia-fernanda@hotmail.com

Kamilla Dourado de Abreu

Faculdade Guaraí, Brasil

http://lattes.cnpq.br/7940990041131369

kamilladouradodeabreu@gmail.com

Simone Possas Andrade

Faculdade Guaraí, Brasil

http://lattes.cnpq.br/0552128506796918

simone.andrade@faculdadeguarai.com.br
Received: 09/04/2017

Approved: 15/07/2017

Referencing this:

VENCESLAU, K. F. R.; ABREU, K. D.; ANDRADE, S. P.; CARVALHO, A. V. RODRIGUES, F. A.; GUIMARÃES, A. P. M.. Tuberculose respiratória: histórico, atualização do diagnóstico e dificuldades do tratamento. Scire Salutis, v.7, n.1, p.38-52, 2017. DOI: http://doi.org/10.6008/SPC2236-9600.2017.001.0004 


\section{INTRODUÇÃO}

Desde a história do homem na terra a ciência tem conhecimento das diversas doenças que acometem a espécie humana. Dentre estas inúmeras doenças encontra-se a Tuberculose (TB) respiratória, que afeta a humanidade com registros desde a pré-história até a atualidade (CAMPOS et al., 2001). A TB é uma patologia causada por uma bactéria denominada Mycobacterium tuberculosis que afeta principalmente as vias respiratórias do indivíduo (TORTORA et al., 2012).

Na literatura existem informações a cerda de indícios desta doença desde o Egito Antigo, sendo estes, os primeiros registros considerados de extrema relevância para explicar a presença do bacilo em uma população tão antiga (ROSEN, 1994). Estes vestígios foram encontrados em 44 múmias que estavam em ótimo estado de preservação, com datas aproximadas entre 3.700 a 1.000 a.C. (método de carbono 14) (ROSEMBERG, 1999).

A revelação da existência de um agente causador da Tuberculose ocorreu em 1882, quando Robert Koch exibiu para o mundo o primeiro isolamento de uma bactéria que provavelmente poderia ser a responsável pela doença, descrita na atualidade como Mycobacterium tuberculosis (MADIGAN et al., 2016), anteriormente denominada por Robert como bacilo de Koch, homenageando o seu próprio nome.

Mycobacterium tuberculosis é uma bactéria com morfologia celular em forma de bastão (bastonete) delgado com respiração aeróbica obrigatória (TORTORA et al., 2012) e são classificadas como ácido-álcoolresistentes pois não podem ser coloridas pelo método convencional de coloração de gram devido a quantidade de lipídios e ácido micólico existente em sua parede celular, sendo necessário realizar o método de coloração de Ziehl-Neelsen para a sua identificação.

Esta bactéria possui período de replicação lenta, com crescimento colonial que raramente formam filamentos e tendem a crescer em cachos (MADIGAN et al., 2016). Comparando o período de replicação de M. tuberculosis com a manifestação dos primeiros sintomas, estes surgem, logo após a infecção, entre 30 a 60 dias após o ciclo de contaminação, tornando o bacilo capaz de ser transmitido a outros indivíduos através dos aerossóis expelidos no ambiente por pacientes infectados (SIQUEIRA, 2012).

De acordo com o Boletim Epidemiológico de 2014, publicado pela Secretaria de Vigilância em Saúde, releva que atualmente no Brasil, a tuberculose ainda é considerada um problema de saúde pública, e está intimamente ligada com a miséria e a desigualdade social (BRASIL, 2014). Dados publicados pela Organização Mundial de Saúde (OMS) em 2013 apontam os países que ocupam até o 22ㅇ lugar quanto ao número de casos confirmados de tuberculose, o que representam $80 \%$ das infecções por $M$. tuberculosis a nível global, sendo que, nesta tabela dos países que apresentaram o maior número de casos confirmados da doença, o Brasil ocupa a 16a posição. Só em 2013, foram registrados 71.123 novos casos de TB no território brasileiro (BRASIL, 2014).

De acordo com Chirinos et al. (2011) os principais fatores que colaboram para os altos índices de Tuberculose no mundo seria a inexistência ou ineficiência do correto diagnóstico em pacientes suspeitos da doença e o abandono do tratamento, ocasionando a ininterrupção da cadeia de transmissão por entre a 
população. Ainda de acordo com o mesmo autor, a realização de um diagnóstico precoce em pacientes suspeitos de infecção por tuberculose pulmonar poderia ser suficiente para o controle da doença, caso seja associado aos resultados positivos o tratamento quimioterápico mais indicado. Pois de acordo com dados publicados pela World Health Organization em 2015, a eficácia do diagnóstico para a Tuberculose e o correto tratamento da doença, foram capazes de salvar 43 milhões de pessoas em todo o mundo entre os períodos de 2000 a 2015 (WHO, 2015).

Segundo Campos (2006), para que ocorra a eliminação por completo do bacilo no hospedeiro é importante que haja um fornecimento de medicamentos sem interrupções, e também a presença de um profissional da saúde que acompanha o paciente com as indicações de utilização do medicamento. Quanto mais rápido o diagnóstico e o início do tratamento menor as chances de uma pessoa disseminar o bacilo na sua comunidade e infectar outas pessoas.

O presente trabalho tem por objetivo realizar uma extensa revisão da literatura, reunindo em um único documento a abordagem da atualização do diagnóstico da tuberculose respiratória, assim como as dificuldades do tratamento da doença e sua história por entre a humanidade.

\section{METODOLOGIA}

O presente trabalho trata-se de uma extensa revisão da literatura de caráter qualitativo, descritivo e exploratório que utilizou como base de pesquisa de dados, artigos científicos com no máximo 5 anos de publicação em revistas eletrônicas e periódicos (dados do Ministério da Saúde, Scielo, Lilacs, Google acadêmico, MEDLINE, Biblioteca Virtual de Saúde, nos sites SCImago, Capes e CNPq), para abordagem atual sobre os últimos diagnósticos voltados a presença do Mycobacterium tuberculosis em seus prováveis hospedeiros, as dificuldades do tratamento e a relação entre estes dois parâmetros com o número de casos confirmados nos últimos anos. Também foram utilizados artigos com publicações anteriores a 2012 para embasar os dados históricos da doença, utilizando as seguintes palavras-chaves: Mal do século, Mycobacterium tuberculosis, baciloscopia, abreugrafia e PCR. Além da utilização de periódicos, também foram utilizados livros, documentos, sites específicos com abordagem do assunto.

\section{DISCUSSÃO TEÓRICA}

\section{Histórico do Mycobacterium tuberculosis e o seu primeiro isolamento}

A tuberculose é uma das infecções respiratória mais antiga da história do homem na terra, com vestígios registrados desde a pré-história, com idade comprovada por meio do método de datação do carbono 14, realizado em múmias encontradas em várias regiões do mundo (CAMPOS et al., 2001).

Segundo Kappelman et al. (2008) o primeiro registro da presença de $M$. tuberculosis na humanidade, trata-se de uma fraca evidência, que diz respeito simplesmente a lesões que são compatíveis com aquelas causadas por tuberculose óssea, que foram encontradas em crânios de esqueletos na Turquia, com datas aproximadas de 500.000 anos de idade. Foram detectadas também, lesões nos esqueletos de múmias 
datadas a pelo menos 5.000 a.C. que são compatíveis com aquelas causadas pelo Mycobacterium tuberculosis em pacientes positivos para a presença do bacilo pulmonar ou extrapulmonar em diagnósticos da atualidade (HIJJAR et al., 2006; MACIEL et al., 2012).

De acordo com Rosemberg (1999), existem outras evidências de que o M. tuberculoses convive com a espécie humana por longos períodos de sua história na Terra, pois foram encontradas 44 múmias em ótimo estado de preservação, datadas a pelo menos 3.700 a 1.000 a.C. todas encontradas na região de Tebas, em que a maioria era de representantes da 21a dinastia do Egito (MORSE et al., 1964; CAVE, 1939). Uma destas múmias apresentava as vias respiratórias e os pulmões em ótimo estado de preservação, o que facilitou a identificação de lesões pleuropulmonares e a existência de sangue na traqueia, tal descoberta revelou que muitas dessas múmias eram faraós e morreram muito jovens, provavelmente acometidos pela doença (ROSEMBERG, 1999).

A primeira evidência incontestada de $M$. tuberculosis foi obtida por meio da técnica de Reação da Polimerase em Cadeira (PCR), realizado a partir do sequenciamento e deteç̧ão de lipídios micobacterianos em lesões ósseas de um bisão de 17.000 anos de idade encontrados em Wyoming, nos Estados Unidos da América (ROTHSCHILD et al., 2001).

Após estas descobertas, muitos outros trabalhos foram realizados em busca de confirmar a presença de tuberculose humana em vários locais de sepultamento na Europa e na Ásia, onde foram encontrados evidências de $M$. tuberculosis em esqueletos de uma criança e em uma mulher em um estabelecimento no Mediterrâneo oriental, com 9.000 anos de idade (DONOGHUE et al., 2004; NICKLISCH et al., 2012; HERSHKOVITZ et al., 2008).

Os primeiros registros da Tuberculose na América do Sul foram datados na Era pré-colombianos, onde foram encontraram múmias no Perú com vestígio de lesões causadas pelo bacilo de Koch que morreu há cerca de 1.100 anos a.C. e 900 d.C., da qual foram extraídos fragmentos de tecidos e estudados a partir de técnicas de PCR, onde foram detectados sequências de DNA compatíveis com o material genético do Mycobacterium tuberculosis (MACIEL et al., 2012; DANIEL, 2000; ROSEMBERG, 1999; HIJJAR et al., 2006). De acordo com Maciel et al. (2012) provavelmente, esta seria a primeira evidência da presença da tuberculose na era pré-colombiana no continente americano.

De acordo com Hijjar et al. (2006) no território brasileiro não tem nenhuma evidência do bacilo nas populações indígenas antes da colonização europeia em 1.500 e que muitos destes colonizadores adentraram as terras brasileiras, atraídos pela qualidade do clima, que era um dos fatores importantes, prescritos por médicos da época para o tratamento da doença.

Os primeiros escritos a respeito da Tuberculose foram encontrados em um livro (De contagione et contagiosis morbis et curatione) escrito pelo médico italiano Girolamo Fracastoro em 1546, que descreve as características de contágio da doença (MASSALONGO, 1917). Já em 1865, Jean-Antoine Villemin, um médico do exército francês, descreve complementando as informações de Fracastoro as formas de transmissão da tuberculose (VILLEMIN, 1865; 1868), e em 24 de Março de 1882, Robert Koch exibiu para o mundo o primeiro isolamento e cultivo do Mycobacterium tuberculosis $(\mathrm{KOCH}, 1882)$ e identificou o agente etiológico como o 
causador da tuberculose, onde passou a ser chamado de bacilo Koch fazendo uma homenagem ao seu nome (SOUZA et al., 2005; VIEIRA et al., 2008; MADIGAN et al., 2016).

\section{Colonização do Brasil e a introdução do bacilo}

A literatura descreve que os primeiros relatos da tuberculose no Brasil ocorreram no período colonial com a chegada dos jesuítas em terras brasileiras e em seguida com os colonizadores portugueses a partir do ano de 1.500 (RUFFINO-NETTO, 2002). Indícios históricos apontam que Padre Manoel da Nóbrega, como um dos primeiros portadores da doença no território brasileiro por volta de 1549 (CAMPOS et al., 2001).

Ao entrar em contato com os índios para catequizá-los, o Padre transmitia a doença aos nativos (HIJJAR et al., 2006; MACIEL et al., 2012). Em cartas enviadas à realeza de Portugal, por Inácio de Loyola em 1555 e por José de Anchieta em 1583 relataram que os índios ao serem catequizados adoeciam, com febre alta, tossindo e expectorando sangue, onde muitos morriam abandonados pelas aldeias (RUFFINO-NETTO et al., 1981).

Neste período, muitas pessoas com tuberculose migraram de seus países para as terras brasileiras por acreditarem que o clima tropical do Brasil Colônia seria fundamental para o tratamento da doença e consequentemente curarem-se da tuberculose (HIJJAR et al., 2006). No período do Brasil Império, acreditavase que a mortalidade por tuberculose, em 1855, se aproximava de um para cada cento e cinquenta habitantes (1/150 habitantes) (CAMPOS et al., 2001). A partir destes resultados, o setor público de saúde passou a prestar maior dedicação a doença, através da participação do Dr. Francisco de Paula Cândido, o qual, passou a ser o presidente da Junta Central de Higiene do Império, obteve a aprovação dos Parlamentares para executar medidas sanitárias voltadas ao controle da tuberculose no território brasileiro (MACIEL et al., 2012).

Após a autorização concedida pelo Parlamento Imperial, Dr. Francisco passou a exercer sua função visando à abordagem das condições de higiene das habitações populares coletivas, conhecidas na época por "cortiços" e das epidemias de tuberculose, e de outras doenças comuns no Rio de Janeiro em 1870 (RUFFINONETTO et al., 1981). Ainda segundo o mesmo autor, na época as diversas leis voltadas para o controle da doença envolviam as condições habitacionais e questões sanitárias, contabilizando no total 5 decretos e 1 aviso ministerial, que estabeleciam regras para os serviços de saúde nas cidades.

No século XIX, a tuberculose se disseminou rapidamente, causando um notável índice de mortalidade, sendo denominada "a praga dos pobres", devido sua forte relação com moradias em estados inadequados e com uma grande quantidade de moradores, com falta de higiene pessoal e sanitária, alimentação deficiente, sendo estes, os elementos observados nas populações da época, também conhecidas como a doença que acometia os artistas e os intelectuais, e passou a ser relacionada ao estilo de vida dos boêmios, sendo intitulada como "a doença dos românticos" (SHEPPARD, 2001; SOUZA et al., 2005).

De acordo com Maciel et al. (2012) os problemas com relação a esta doença eram ainda mais complicados no século XIX, pois neste período ocorreu uma rápida urbanização dos grandes centros e os serviços de saúde e sanitários apresentavam-se de forma insuficiente.

Ainda no século XIX, uma das entidades que apresentavam grande importância para a sociedade 
brasileira no combate a tuberculose foram as Santas Casas de Misericórdia, pois atendiam pacientes portadores da doença desde o período da colonização do Brasil, até a elaboração dos sanatórios e dos dispensários a partir de 1920 (CAMPOS et al., 2001; BELCULFINÉ, 2009). Estas irmandades tinham como fundamento principal uma concepção humanitária, amparando aqueles que não possuíam condições financeiras de se manter, ofertando às estas pessoas inúmeros mantimentos, inclusive alimentos e remédios (RESENDE et al., 2006).

Essa epidemia se agravou por muitos anos, aumentando cada vez mais o número de pessoas contaminadas (MACIEL et al., 2012). Somente a partir de 1940 os primeiros tratamentos foram administrados aos doentes (FILHO, 2001). Até os dias atuais os índices de mortalidade não foram erradicados, isso devido a diversos fatores que influenciam direta ou indiretamente a presença do bacilo por entre a humanidade, tais como a desigualdade social, a multirresistência do bacilo e a epidemia da AIDS (MACIEL et al., 2012).

\section{Dificuldades do tratamento}

No decorrer de 3 milênios, não existia um tratamento específico e eficaz contra a tuberculose, foram muitas as alternativas empíricas utilizadas para o tratamento desta doença. Os primeiros métodos utilizados eram denominados "septeto de panáceia", que constituía um conjunto de 7 (sete) medidas médicas para a realização do tratamento em pacientes suspeitos da doença, estes métodos eram cruéis, românticos ou até mesmo eróticos e consistiam em: sangrias, purgativos, ventosas, eméticos, vesicatórias, sanguessugas e clisteres (ROSEMBERG, 2000).

O primeiro medicamento farmacológico utilizado para o tratamento da TB foi mediado pela descoberta da estreptomicina e do ácido para-amino-salićlico no ano de 1944, a eficácia destes medicamentos foi comprometida pela descoberta da resistência bacteriana a estas drogas (CAMPOS, 2007).

Após o conhecimento da estreptomicina, a ciência descobriu uma interação medicamentosa entre a isoniazida e rifampina, onde, a utilização destes dois compostos apresentava efeitos positivos para o tratamento desta doença (NATAL et al., 2003). O tratamento habitual se procede com a administração destas duas drogas por um período compreendido de 2 meses sem interrupção, seguida de doses bissemanais por um período total de 9 meses (MADIGAN et al., 2016).

Já em 1980 o Brasil foi o primeiro país no mundo a inserir a terapia medicamentosa com duração ininterrupta de 6 meses, utilizando isoniazida, rifampina, pirazinamida e etambutol (WILDNER, 2011). Sendo que, nos 2 (dois) primeiros meses de tratamento são utilizadas as três primeiras drogas concomitantemente, sendo considerada a primeira linha do tratamento. Nos 4 (quatro) seguintes meses, administra-se, somente a rifampina e isoniazida, com duração ininterrupta de 6 meses, o etambutol é recomendado para pacientes que apresentam resistência a primeira linhagem do tratamento (MADIGAN et al., 2016; CAMPOS et al., 2001).

No entanto, no final do século XIX, o tratamento da TB foi drasticamente abalado pela descoberta de uma co-infecção com um vírus, que minimizava as chances de cura dos pacientes. Em 1981 foi descoberta a existência de um retrovírus que afeta o sistema imunológico dos seres humanos, denominado HIV, do qual foi observado, um abrupto aumento no número de pessoas contaminadas por $M$. tuberculosis devido à esta 
co-infeç̧ão com HIV em pacientes bacilíferos positivos, tornando-o multidrogaresistente, ou seja, sem nenhum tipo de tratamento quimioterápico capaz de combater a Tuberculose em pacientes também contaminados pelo HIV (CAMPOS et al., 2001).

Segundo dados publicados pelo Boletim Epidemiológico, em 2010 do total de novos casos de tuberculose notificados no Sistema de Informação de Agravos de Notificação (Sinan), em torno de 10\% foram confirmados com co-infecção entre a Tuberculose (TB) e o Vírus da Imunodeficiência Adquirida (HIV) (BRASIL, 2012).

De acordo com Ribeiro et al., (2000) quando se fala em tuberculose, uma das principais preocupações com relação a resistência do bacilo, está intimamente ligada ao abandono do tratamento por parte dos pacientes. Este autor esclarece ainda, que no Brasil esse índice é alto girando em torno de $17 \%$. A decisão de interrupção do tratamento da Tuberculose gera uma drástica consequência, pois com o abandono o paciente não interrompe a cadeia de transmissão e continua disseminando a Tuberculose a outros pacientes que não apresentavam sintomas e que pode desenvolver a doença já com habilidade em se tornar resistente ao medicamento graças ao contato primário da bactéria com o tratamento (MENDES et al., 2004).

De acordo com o Boletim Epidemiológico, o caso de abandono do tratamento da Tuberculose no Brasil em 2014 ainda expressou um índice de desistência do tratamento relativamente alto, com 11\% de casos confirmados em todo o território brasileiro, onde todos os Estados pertencentes à Federação, exceto o Acre e o Amapá apresentaram índices de abandono acima daqueles preconizados pela Organização Mundial de Saúde (>5\%) (BRASIL, 2016).

Mendes et al. (2004) afirmam que o abandono do tratamento é um fator decisivo, pois leva o doente à resistência medicamentosa e a reincidente da doença, onde se pode notar um declínio no processo de cura, e assim prolongando o tempo e o custo do tratamento.

\section{Atualização do diagnóstico}

Com o passar do tempo, na história da tuberculose, foram desenvolvidas e adaptadas muitas metodologias e equipamentos para diagnosticar a presença do bacilo nos indivíduos acometidos pela doença (Tabela 1) e poder administrar o melhor tratamento aos pacientes bacilíferos positivos. Dentre estes métodos aplicados, estão envolvidos desde os exames de cultura (os mais simples e baratos) até exames mais atualizados e precisos como Reação da Cadeia de Polimerase (PCR), os mais eficazes para diagnosticar a doença, porém os mais caros existentes no mercado atualmente (FERRI et al., 2014).

Tabela 1. Descrição mínima sobre a evolução do diagnóstico da Tuberculose Respiratória durante a história da doença no ser humano.

\begin{tabular}{c|l}
\hline \multicolumn{1}{c|}{ DIAGNÓSTICO } & \multicolumn{1}{c}{ DESCRIÇÃO } \\
\hline \multirow{3}{*}{ Os primeiros diagnósticos } & $\begin{array}{l}\text { Os primeiros diagnósticos eram realizados pela simples observação das manifestações sintomáticas } \\
\text { das doenças nos pacientes, seguindo as recomendações da Classificação Internacional de Doenças } \\
\text { (OPS, 1998). Assim, o primeiro diagnóstico da Tuberculose estava intimamente ligado a presença de } \\
\text { febre ao entardecer, tosse prolongada e presença de sangue no escarro. }\end{array}$ \\
\hline Baciloscopia & $\begin{array}{l}\text { Consiste na coloração do Mycobacterium tuberculosis, empregando diferentes tipos de corante para } \\
\text { a identificação do bacilo em tecidos contaminados (MADIGAN et al. 2016). }\end{array}$ \\
\hline
\end{tabular}




\begin{tabular}{l|l}
\hline Cultura & $\begin{array}{l}\text { Só a identificação do bacilo em tecidos contaminados não era suficiente, então foi criando uma } \\
\text { metodologia por Robert Kock para isolar o agente causador da doença, utilizando um meio de cultura } \\
\text { contendo soro sanguíneo coagulado (MADIGAN et al. 2010). }\end{array}$ \\
\hline \multirow{3}{*}{ Tuberculina } & $\begin{array}{l}\text { Outro diagnóstico descoberto por Robert Koch, que consiste em identificar os sintomas produzidos } \\
\text { pelos pacientes acometidos pela Tuberculose a partir da produção defesas contra a bactéria, que é a } \\
\text { principal base para o teste de tuberculina, pois, a tuberculina é uma proteína purificada derivada da } \\
\text { tuberculose, resultante da precipitação de culturas em caldo, que pode ser inseridas cultaneamente, } \\
\text { assim, pacientes com infecções prévias, apresentam resultado tuberculina-positiva (SILVEIRA, 1941; } \\
\text { MADIGAN et al. 2010). }\end{array}$ \\
\hline Radiologia & $\begin{array}{l}\text { Um tipo de diagnóstico realizado a parti de Raio-X, pois nas imagens é possível observar a devastação } \\
\text { que o Mycobacterium tuberculosis causa nos pulmões dos pacientes acometidos pela doença } \\
\text { (CAPONE et al. 2006). }\end{array}$ \\
\hline Abreugrafia & $\begin{array}{l}\text { Este método de diagnóstico foi desenvolvido no Brasil, pelo Médico Manoel Dias de Abreu, trata-se } \\
\text { de um diagnóstico embasado na fluorografia, com imagens mais precisas da presença do bacilo em } \\
\text { pacientes bacilíferos positivos (BOMBARDA et al. 2001). }\end{array}$ \\
\hline Consiste na amplificação da sequência do material genético de qualquer organismo a partir de uma \\
quantidade mínima de DNA (ácido desoxirribonucléico) ou RNA (ácido ribonucleico) (BOLLELA et al. \\
2001).
\end{tabular}

Fonte: Venceslau et al. (2017).

\section{Os primeiros diagnósticos}

De acordo com a Classificação Internacional de Doenças, os primeiros diagnósticos realizados para classificar as doenças eram de acordo com as manifestações mais importantes da doença no paciente, ou seja, alocava-se a afeç̧ão de acordo com a manifestação de acordo com a classificação tradicional, segundo a etiologia (OPS, 1998). Sendo aprovado o diagnóstico de acordo com o ponto de vista de diferentes médicos, atribuía-se assim, o código que era correspondente aos sintomas apresentados pelo paciente em seu prontuário, e estes eram encaminhados ao tratamento indicado para aquela enfermidade.

\section{Baciloscopia}

Robert Koch começou seus estudos sobre a tuberculose em 1881, a fim de demonstrar qual microrganismo era o causador daquela enfermidade. Para evidenciar a existência do bacilo causador da doença, Koch utilizou todos os métodos já empregados em estudos anteriores, como: microscopia, coloração, isolamento em culturas puras e um sistema de modelo animal.

Koch utilizou um fragmento de um tecido infectado e assim realizou a primeira coloração do Mycobacterium tuberculosis, empregando azul de metileno alcalino juntamente com outro corante, hoje conhecido como (marrom de Bismarck), com isso pôde observar as células bacilares do M. tuberculosis (MADIGAN et al., 2016).

Com o passar do tempo essa coloração foi sendo aperfeiçoada por outros pesquisadores e assim chegando às colorações de Ziehl-Neelsen, Kinyoun com adaptações, auramina-O e rodamina, sabendo que, a coloração de Ziehl-Neelsen é a mais utilizada no diagnóstico da tuberculose atualmente. Essa metodologia consiste em um esfregaço de uma lâmina com o material biológico do paciente "escarro" (FILHO et al., 2004).

$\mathrm{Na}$ técnica de Ziehl-Neelsen, a amostra contendo o material biológico do doente é corada inicialmente com fucsina de Ziehl-Neelsen, aquecida em chama por 5 minutos com 3 intervalos de 1 minuto entre um aquecimento e outro, logo após descorada com álcool-ácido e em seguida corada com azul de metileno (FERRI, 2014). Para que o resultado seja considerado positivo neste tipo de diagnóstico, é necessário 
encontrar no mínimo 5.000 bacilos por mililitro de escarro (CAMPOS, 2006).

O método de Kinyoun é uma variação do método de Ziehl-Neelsen, (com a eliminação do processo de aquecimento) e a coloração é fluorescente com auramina (BARRETO et al., 2006). Os dois métodos se fundamentam na propriedade dos bacilos serem álcool-ácido-resistente, isto é, após ser corado pela fucsina básica, permanecerem com as cores vermelha ou rósea, mesmo, depois de serem expostos ao efeito de solução de ácido clorídrico a 3\% em álcool, para descoloração (FILHO et al., 2004).

A fusão entre auramina-O com rodamina foi realizada em 1946 por Hugles (ROSEMBERG, 1990). Essa técnica passou por diversas transformações no corante e no tempo de coloração. Estes corantes são considerados inespecíficos fluorescentes sobre a luz violeta (Ministério da Saúde, 1994), tratando-se de uma coloração similar a colorações convencionais usando fucsina, com a vantagem de ser visualizadas com menor aumento, observando os espécimes em menos tempo e sua sensibilidade é de $95,6 \%$ e especificidade de $98 \%$ (ROBLEDO et al., 2011).

\section{Cultura}

Ainda no ano de 1881, logo após a descoberta do agente etiológico Mycobacterium tuberculosis, Robert Koch percebeu que só identificar o agente causador da tuberculose não era o suficiente, ele tinha que isolar o bacilo a fim de provar o seu relacionamento com aquela enfermidade, até então uma doença misteriosa (ANERIK, 1974). Para alcançar culturas puras do M. tuberculosis não foi nada fácil, mas finalmente ele conseguiu isolar o agente causador, utilizando um meio de cultura contendo soro sanguíneo coagulado (MADIGAN et al., 2010). A partir deste momento, Robert Koch comprovou a relação entre o bacilo e a doença (TORTORA et al., 2012).

$\mathrm{Na}$ atualidade a cultura do escarro é o método padrão ouro no diagnóstico da tuberculose pulmonar, a sua sensibilidade e especificidade são bastante altas, as semeaduras são feitas em meios sólidos onde os mais utilizados nesse processo é Lowenstein-Jensen (L) e o Ogawa-Kudoh (BRASIL, 2008). Mesmo sendo um diagnóstico padrão ouro existe a sua desvantagem, pois para este método de diagnóstico, os isolados levam cerca de 2 a 8 semanas para o crescimento das colônias, tardando assim o diagnóstico e interferindo em sua eficácia (BRASIL, 2011) e no início imediato do tratamento e consequentemente na interrupção da cadeia de transmissão.

No ano de 1974, indicaram uma maneira simplificada para descontaminação de espécime de escarro, que utiliza o swab algodão e hidróxido de sódio, com semeadura direta em meio de cultura Ogawa (OLIVEIRA et al. 2011). O preparo dura cerca de 3 a 4 minutos por amostra, não precisa centrifugar e também não é necessária à utilização de uma cabine de segurança biológica para inocular o bacilo no meio de cultura.

O Bactec é um teste de cultura, usando um meio líquido e radiométrico marcado com 14C-palmitato como fonte exclusiva de carbono (OTAL et al., 1997). Sua comercialização ficou disponível por quase vinte anos (CAMPOS, 2006). Campos (2006) esclarecem ainda que, a expansão da utilização desse sistema rápido e semi-automatizado provocaram vários transtornos relacionados aos resíduos de radioisótopos no ambiente. 
Devido aos problemas causados, foram desenvolvidos novos sistemas para a substituição do Bactec 450, sendo eles; Bactec 460 que detecta $\mathrm{CO}_{2}$ radiomarcado liberado no meio pela replicação bacteriana, em seguida surgiram Bactec 9000, o MGIT 960 e o método da cultura ESPII, que estão sendo utilizados atualmente em laboratórios de alto e médio porte para o diagnóstico da tuberculose, que apresentam como vantagem a isenção de uma cabine de segurança biológica para a inoculação do bacilo (FILHO et al., 2004; CAMPOS, 2006).

Os testes bioquímicos mais utilizados para a confirmação do Mycobacterium tuberculosis são: crescimento e produção de pigmentação, temperatura, catalasesemi-qualitativa e teste de sensibilidade (BRASIL, 2004).

Dentre todos os testes utilizados para identificar a presença do agente causador da tuberculose em materiais biológicos, existem também, aquele utilizado para identificar bactérias resistentes aos quimioterápicos administrados nos pacientes em tratamento da doença (TORTORA et al., 2012).

Alexandre Fleming foi quem fundamentou o teste de sensibilidade das bactérias a alguns compostos sintetizados por certos organismos, quando em 1928 observou que um bolor ao contaminar uma placa de petri que continha o isolado de Staphiococcus aureus formou um halo de inibição do crescimento desta bactéria em torno da colônia do bolor (KRIEG, 1997). Fleming então identificou este fungo como Penicillum notatum e o seu composto ativo de Penicilina, o primeiro antibiótico descoberto no mundo, ao qual fundamenta a base da farmacologia para todos os outros antibióticos conhecidos hoje em dia.

Existem vários estudos que apontam isolados de M. tuberculosis, resistentes a estes medicamentos, dificultando o sucesso do tratamento para pacientes resistentes, sendo necessária a interação de outros medicamentos ao tratamento na expectativa de cura da doença (CAMPOS, 1999; ROSSETTI et al., 2002).

\section{Tuberculina}

A descoberta da tuberculina e o seu papel no diagnóstico do contágio da tuberculose originaram-se nas ideologias pastorianas. Essa então descoberta aconteceu em 1890, sendo que, os primeiros a trabalharem com este teste diagnóstico denominaram-na como linfa. Robert Koch ao descobrir esse novo diagnóstico, ficou entusiasmado, pois os resultados confirmaram ter descoberto a tão esperada vacina para a imunização contra a tuberculose (SILVEIRA, 1941).

Os pacientes da tuberculose produzem defesas contra a bactéria, que é a principal base para o teste de tuberculina, porém, não significa que os casos positivos para este método de diagnóstico o paciente esteja infectado, pois, a tuberculina é uma proteína purificada derivada da tuberculose, resultante da precipitação de culturas em caldo, que pode ser inseridas cutaneamente, assim, pacientes com infecções prévias, apresentará o resultado tuberculina-positiva, o que não indica necessariamente que esteja contaminado pelo bacilo, mas sim, que já entrou em contato com este no passado, por este motivo é um teste indicado somente para pacientes que tiveram o primeiro contato com a vacina BCG (MADIGAN et al., 2010).

O principal problema com relação ao teste de tuberculina é que os pacientes infectados anteriormente reagem em 48 horas com esta proteína, apresentando hipersensibilidade tardia, através das 
células " $T$ " sensibilizadas, representada por meio de um enrijecimento e vermelhidão no local de inoculação (BRASIL, 2002).

O teste mais eficaz da tuberculina é denominado mantoux, executado com a diluição de $0,1 \mathrm{ml}$ do antígeno que são introduzidos de forma intradérmica, e o local de reação é medido (BRASIL, 1995). Mesmo com eficácia comprovada, este método passou por atualizações ao longo dos anos.

Com o tempo, outros métodos com melhor eficácia e que causavam menor transtorno a saúde dos pacientes foram criados, como por exemplo, o teste de interferon-gama (IGRA), que se tornou um dos substitutos do teste tuberculínico. Este teste realiza a quantificação in vitro da resposta imunológica da célula que possam identificar o interferon-gama, ou seja, uma citosina emitida pelas células T, que são sensíveis ao estímulo com antígenos do M. tuberculosis (TORTORA et al., 2012).

\section{Radiologia}

O raio-X foi criado em 1895 pelo físico alemão Wilhelm Conrad Rontgen (MARTINS, 1998). No Brasil o primeiro aparelho chegou em 1897, com aspecto bastante robusto, necessitando de pilhas e baterias para seu funcionamento que, posteriormente foi necessário adaptar um motor fixo que gerava energia unicamente para o funcionamento deste aparelho. As primeiras imagens foram feitas com chapas de vidro, entre 1899 e 1912 (FRANCISCO et al., 2006).

Já no ano 1936, o Brasil se destacou com a descoberta do Médico Manoel de Abreu, que criou um aparelho denominado abreugrafia que utilizava a radiologia e fotografia para o diagnóstico e tratamento da tuberculose pulmonar (SBP, 2001). Esse método foi vastamente utilizado no decorrer da segunda guerra mundial (BOMBARDA et al., 2001).

$\mathrm{Na}$ atualidade o Raio-X agregado a outras metodologias, apresentam grande valor no diagnóstico da tuberculose, pois nas imagens geradas por este aparelho é possível observar a devastação que o Mycobacterium tuberculosis causa nos pulmões do paciente suspeito da infecção (CAPONE et al., 2006). Essas alterações podem ser a partir de cavitações, padrão miliar, adenopatias, derrame pleural e atelectasias (CAPONE et al. 2012). Quando se tem uma co-infecção entre pacientes HIV positivos e tuberculose, essas alterações podem evoluir para infiltrados nos lobos inferiores, linfadenopatias hilares e derrames pleurais (FERRI, 2014).

\section{Abreugrafia}

Este método de diagnóstico foi desenvolvido no Brasil, pelo Médico Manoel Dias de Abreu (BOMBARDA et al., 2001). Manoel em sua terceira tentativa para desenvolver um diagnóstico para a tuberculose criou a fluorografia em 1936. As primeiras imagens desse diagnóstico se mostraram bastante claras. Além disso, possuía um custo relativamente baixo, agora a meta era aplicá-lo em grande escala. Nos anos subseqüentes a fluorografia diagnosticou um número considerável de pacientes. O nome fluorografia passou por diversas modificações até se firmar em abreugrafia, instituído pelo prefeito de São Paulo, Ademar de Barros em 1958. 


\section{$P C R$}

No ano de 1983 Kary Mullis descreveu o método que consiste na amplificação da sequência do material genético de qualquer organismo a partir de uma quantidade mínima de DNA (ácido desoxirribonucléico) ou RNA (ácido ribonucleico). Essa descoberta foi batizada como PCR (Polymerase Chain Reaction) (BOLLELA et al., 2001).

A PCR é uma das técnicas mais próspera no diagnóstico da tuberculose pulmonar, essa metodologia consiste em uma alta sensibilidade e especificidade, fazendo com que os resultados saiam em algumas horas após a realização do teste. É uma técnica que utiliza um aparelho com programações de diferentes temperaturas (termociclador), no intuito de abrir e fechar a fita de DNA por forças térmicas, para amplificar uma região específica do DNA com o auxílio de primers, trifosfato-dinucleotídeos e enzima taq polimerase (BARRETO et al., 2006).

Com a amplificação do ácido nucléico foi possível observar uma melhora expressiva no diagnóstico da Tuberculose Pulmonar, para esse tipo de técnicas estão disponíveis no mercado dois testes: teste de amplificação direta do complexo Mycobacterium tuberculosis (AMTD) e o Amplicor $^{T M}$ (ASSIS et al., 2004).

O primeiro teste utiliza uma sonda de DNA e o segundo uma reação colorimétrica. Outras metodologias mais recentes que se baseia na PCR em tempo real, já estão disponíveis no mercado, voltadas a hibridização dos ácidos nucléicos amplificados com sonda fluorescente iluminação Ultravioleta (CAMPOS, 2006).

Essa técnica consiste em uma sensibilidade e especificidade próximas a $100 \%$, os resultados ficam prontos entre uma hora e meia a duas horas após a realização do teste. Quando essa metodologia é empregada em material não pulmonar sua especificidade é de $100 \%$ e sua sensibilidade de 93 a $94 \%$. Outra técnica disponível é a BDProbeTec $M T B^{T M}$, trata-se de um método semi-automatizado que sua reação se baseia na replicação enzimática, sua sensibilidade e especificidade também é próximo a 100\%, e o resultado sai em até 2 horas (CAMPOS, 2006).

\section{CONSIDERAÇÕES FINAIS}

Diante das informações abordadas durante todo o trabalho, conclui-se que, o tratamento da tuberculose em relação aos vários métodos de diagnóstico da doença, apresenta-se sem significantes modificações em sua formulação por um período aproximado de 72 anos, desde a descoberta dos fármacos, estreptomicina e ácido-para-amino-salicílico, permanecendo o mesmo desde então, modificando somente a interação com outros medicamentos e o tempo estipulado para o tratamento mediante a gravidade apresentada por cada paciente. Deste modo destaca-se a necessidade da implantação de novos tratamentos alternativos, visando à existência de cepas resistentes, provavelmente gerados a partir do abandono do tratamento pelo paciente ou pela co-infecção com outros agentes infecciosos, como por exemplo, o HIV. 
Diferente do tratamento o diagnóstico passou por uma longa adaptação, tornando-o extremamente preciso, emergindo desde a simples baciloscopia (utilizada na antiguidade até a atualidade pelo Sistema Único de Saúde) até atual e precisa e atual PCR.

\section{REFERÊNCIAS}

ANERIK, A. I.. Estudio experimental sobre el diagnóstico de la tuberculosis bovina mediante pruebas de cultivo e inoculación animal. Ciencias Veterinarias, v.4, n.1, p.137200, 1974.

ASSIS, N. C. S.; LOPES, M. L.; CARDOSO, N. C.; COSTA, M. M.; SOUSA, C. O.; LIMA, K. V. B.. Diagnóstico molecular da tuberculose pulmonar. J Bras Patol Med Lab, v.43, n.1, p.17, 2007.

BARRETO, A. M.; CALDAS, P. C. S.; CAMPOS, C. E. D.; MARTINS, F. M.. Diagnóstico laboratorial. Revista do Hospital Universitário Pedro Ernesto (UERJ), 2006.

BRASIL. Ministério da Saúde. Manual de Normas para o Controle da Tuberculose. Brasília: 1995.

BRASIL. Ministério da Saúde. Fundação Nacional de Saúde. Guia de Vigilância Epidemiológica. Brasília: 2002.

BRASIL. Agência Nacional de vigilância Sanitária. Detecção e Identificação de Microbactérias de Importância Médica. Brasília: 2004.

BRASIL. Ministério da Saúde. Secretaria de Vigilância em Saúde Departamento de Vigilância Epidemiológica. Manual Nacional de vigilância laboratorial de Tuberculose e outras Microbactéria. Brasília: 2008.

BRASIL. Ministério da Saúde. Secretaria de Vigilância em Saúde Departamento de Vigilância Epidemiológica. Manual de Recomendações para o Controle da Tuberculose no Brasil. Brasília: 2011.

BRASIL. Ministério da Saúde. Secretaria de Vigilância em Saúde. Boletim Epidemiológico: especial Tuberculose, Brasília, v.43, p.12, 2012.

BRASIL. Ministério da Saúde. Secretaria de Vigilância e Saúde. O controle da Tuberculose no Brasil: avanços, inovações e desafios. Boletim epidemiológico, Brasília, v.45, n.2, p.2-13, 2014

BRASIL. Ministério da Saúde. Secretaria de Vigilância e Saúde. Boletim epidemiológico: Perspectivas brasileiras para o fim da tuberculose como problema de saúde pública, Brasília, v.47, n.13, p.15, 2016.

BELCULFINÉ, D. C.. Os sanatórios e seu tempo. Pneumol Paulista, v.22, n.5, p.68-70, 2009.

BOMBARDA S.; FIGUEIREDO, C. M.; FUNARI, M. B. G.; JUNIOR, J. S.; SEISCENTO, M.; FILHO, M. T.. Imagem da Tuberculose Pulmonar. J pneumol, v.27, n.6, p.329-340, 2001.

BOLLELA, V. R.; SATO, D. N.; FONSECA, B. A. L.. Problemas na padronização da reação em cadeia da polimerase para diagnóstico da tuberculose pulmonar. Rev Saúde Pública, v.3, n.3, p.281-286, 1999.

BOMBARDA, S.; FIGUEIREDO, C. M.; FUNARI, M. B. G.; JUNIOR, J. S.; SEISCENTO, M.; FILHO, M. T.. Imagem em tuberculose pulmonar. J pneumol, v.27, n.6, p.329-340, 2001.

CAPONE, D.; JANSEN, J. M.; LOPES, A. J.; SOARES, M. O.; PINTO, R. S.; SIQUEIRA, H. R.; CAPONE, R. B.. Diagnostico Radiográfico e Tomográfico da Tuberculose Pulmonar. Revista Hospital Universitário Pedro Ernesto, v.5, n.2, 2006.

CAPONE, D.; CAPONE, R. B.; SOUZA, R. L. P.. Diagnóstico por Imagem da Tuberculose. Pulmäo RJ, v.21, n.1, p.36-40, 2012.

CAMPOS, R.; PIANTA, C.. Tuberculose: histórico, epidemiologia e imunologia, de 1990 a 1999, e co-infecção TB/HIV, de 1998 a 1999, Rio Grande do Sul-Brasil. Bol. da Saúde, v.15, n.1, p.61-71, 2001.

CAMPOS, H. S.. Mycobacterium tuberculosis resistente: de onde vem a resistência?. Boletim de Pneumologia Sanitária, v.7, n.1, p.51-64, 1999.

CAMPOS, H. S.. Diagnóstico da tuberculose. Pulmão RJ, v.15, n.2, p.92-99, 2006.

CAMPOS, H. S.. Tratamento da tuberculose. Pulmão RJ, v.16, n.1, p.21-31, 2007

CAVE, A. J. E.. The evidence for the incidence of tuberculosis in ancient Egypt. Br J Tuberc, v.33, p.142-152, 1939.

CHIRINOS, N. E. C.; MEIRELLES, B. H. S.. Fatores Associados ao Abandono do Tratamento da Tuberculose: Uma Revisão Integrativa. Texto Contexto Enfim, Florianópolis, v.20, n.3, p.599-606, 2011.

DANIEL, T. M.. The origins and precolonial epidemiology of tuberculosis in the Americas: can we figure them out?. Int J Tuberc Lung Dis, v.4, n.5, p.395-400, 2000.

DONOGHUE, H. D.; SPIGELMAN, M.; GREENBLATT, C. L. Tuberculosis: from prehistory to Robert Koch, as revealed by ancient DNA. Lancet Infect Dis, v.4, p.584-592, 2004.

FERRI, O. A.; AGUIAR, B.; WILHELM, C. M.; SCHMIDT, D.; FUSSIEGER, F.; PICOLI, S. U.. Diagnóstico da tuberculose: uma revisão. Rev. Liberato, v.15, n.24, p.146-154, 2014.

FILHO, A. C.; KRITSKI, A. L.; BARRETO, A. W.; LEMOS, A. C. M.. 20 Consenso Brasileiro de Tuberculose: diretrizes brasileiras para tuberculose 2004. Jornal Brasileiro de Pneumologia, v.30, p.S57-S86, 2004. 
FILHO, C. B.. História Social da Tuberculose e do Tuberculoso: 1900-1950. Rio de Janeiro: Fiocruz, 2001.

FRANCISCO, F. C.; MAYMONE, W.; AMARAL, M. A. V.; CARVALHO, A. C. P.; FRANCISCO, V. F. M.; FRANCISCO, M. C.. História da radiologia no Brasil. Revista Imagem, v.28, n.1, p.63-66, 2006.

HIJJAR, M. A.; PROCÓPIO, M. J.. Tuberculose: epidemiologia e controle no Brasil. Revista Hospital Universitário Pedro Ernesto, v.5, n.2, 2006.

HERSHKOVITZ, I.; DONOGHUE, H. D.; MINNIKIN, D. E.. Detection and molecular characterization of 9000-year-old Mycobacterium tuberculosis from a Neolithic settlement in the Eastern Mediterranean. PloS one, v.3, n.10, p.e3426, 2008.

KAPPELMAN, J.; ALCICEK, M. C.; KAZANCI, N.; SCHULTZ, M.; OZKUL, M.; SEM, S.. First Homo erectus from Turkey and implications for migrations into temperate Eurasia. Am J Phys Anthropol, v.135, p.110-116, 2008.

$\mathrm{KOCH}, \mathrm{R}$.. Die Aetiologie der Tuberkulose. Berliner klinische Wochenschrift, v.15, p.221-230, 1882.

KRIEG, P. C.. Microbiologia Conceitos e Aplicações. 2 ed. v.2. 1997.

MACIEL, M. S.; MENDES, P. D.; GOMES, A. P.; BATISTA, R. S. A história da Tuberculose no Brasil: os muitos tons (de cinza) da miséria. Rev Bras Clin Med., v.10, n.3, p.226-230, 2012.

MADIGAN, M. T.; MARTINKO, J. M.; DUNLAP, P. V.; CLARK, D. P.. Microbiologia de Brock. 12 ed. Porto Alegre: Artmed, 2010.

MADIGAN, M. T.; MARTINKO, J. M.; BENDER, K. S; BUCKLEY, D. H.; STAHL, D. A.. Microbiologia de Brock. 14 ed. Porto Alegre: Artmed, 2016.

MARTINS, R. A.. A Descoberta dos Raios X: O Primeiro Comunicado de Rontgen. Revista Brasileira de Ensino de Física, v.20, n.4, p.373, 1998.

MASSALONGO, R.. Girolamo Fracastoro e la rinascenza della medicina in Italia. II Fracastoro: Gazzeta Medica Veneta, v.13, n.4, p.57-60, 1917.

MENDES, A. M.; FENSTERSEIFER, L. M.. Tuberculose: porque os pacientes abandonam o tratamento?. Bol. Pneumol. Sanit., v.12, n.1, p.25-36, 2004.

MORSE, D.; BROTHWELL, D. R.; UCKO, P. J.. Tuberculosis in ancient Egypt. Am Rev Respir Dis, v.90, p.524-541, 1964.

NATAL, S.; VALENTE, J. G.; SÁNCHEZ, A. R.; PENNA, M. L. F.. Resistência a isoniazida e rifampicina e história de tratamento anterior para a tuberculose. Cad. Saúde Pública, v.19, n.5, p.1277-1281, 2003.

NICKLISCH, N.; MAIXNER, F.; GANSLMEIER, R.. Rib lesions in skeletons from early neolithic sites in Central Germany: on the trail of tuberculosis at the onset of agriculture. Am J Phys Anthropol, v.149, p.391-404, 2012.
OLIVEIRA, M. S. C.; LIMA, C. A. M.; MOURA, M. M. F.. Análise do Método Ogawa-Kudoh e Comparação com Método de Lauril Sufato de Sódio-Lowenstein-Jensen para Diagnóstico da Tuberculose no Estado de Rondônia. Revista Pesquisa \& Criação, v.10, n.2, p.127-137, 2011.

OPS (Organizacion Panamericaca de la Salud). El controle de la tuberculosis en las Américas. Boletín Epidemiológico, v.19, n.2, 1998.

OTAL, I.; SAMPER, S. M.; ASENSIO, M. P.; VITORIA, A. M.; RUBIO, C.; LUS-GOMEZ, R.; MARTINS, C.. Use of a PCR Method Based on IS6110 Polymorphism for Typing Mycobacterium Strains Form BACTEC Cultures. Journal of clinical microbiology, v.35, n.1, p.273-277, 1997.

RESENDE, M. L. C.; SILVEIRA, N. C.. Misericórdias da Santa Casa: um estudo de caso da prática médica nas Minas Gerais oitocentista. História Unisinos, v.10, n.1, p.5-13, 2006.

RIBEIRO, S. A.; AMADO, V. M.; CAMELIER, A. A.; FERNANDES, M. M. A.; SCHENKMAN, S.. Estudo Caso-Controle de Indicadores de Abandono em Doentes com Tuberculose. Jornal de Pneumologia, v.26, n.6, p.1-9; 2000.

ROBLEDO, J. R.; MEJIA, G. I.. Actualidad en el Diagnóstico de Tuberculosis por el Laboratorio. Infectio, v.5, n.4, 2011.

ROSEMBERG, J.; TARANTINO, A. B.; PAULA, A.. Doenças Pulmonares. 3 ed. Rio de Janeiro: Guanabara Koogan, 1990.

ROSEMBERG, J.. Tuberculose: Aspectos Históricos, realidades, seu romantismo e transculturação. Boletim de Pneumologia Sanitária, v.7, n.2, p.5-29, 1999.

ROSEMBERG, J.. Tratamento da Tuberculose quando não havia tratamento. Rev. Fac. Ciênc. Méd. Sorocaba, v.2, n.2, p.34, 2000 .

ROSEN, G.. Uma história da Saúde Pública. São Paulo: Hucitec, 1994.

ROSSETTI, M. L. R.; VALIM, A. R. M.; SILVA, M. S. N.; RODRIGUES, V. S.. Tuberculose Resistente: Revisão Molecular. Revista de Saúde Pública, v.36, n.4, p.525-532, 2002.

ROTHSCHILD, B. M.; MARTIN, L. D.; LEV, G.. Mycobacterium tuberculosis complex DNA from an extinct bison dated 17,000 years before the present. Clin Infect Dis, v.33, p.305311, 2001.

RUFFINO-NETTO, A.. Tuberculose: A Calamidade Negligenciada. Revista da Sociedade Brasileira de Medicina Tropical, v.35, n.1, p.51-58, 2002.

RUFFINO-NETTO, A.; PEREIRA, J. C.. Mortalidade por tuberculose e condições de vida: o caso Rio de Janeiro. Rev Saúde Debate, v.12, n.1, p.27-34, 1981.

SHEPPARD, D. S.. A literatura médica brasileira sobre a peste branca: 1870-1940. Hist Ciênc Saúde, v.8, n.1, p.172-92, 2001.

SIQUEIRA, H. R.. Enfoque Clínico da Tuberculose Pulmonar. Pulmão RJ, v.21, n.1, p.15-18, 2012. 
SILVEIRA, D. R. H.. Reações de tuberculina: sua interpretação, seu valor no diagnóstico da tuberculose. Revista de Medicina, v.25, n.89, p.29-52, 1941.

SBP. Publicação Oficial da Sociedade brasileira de Pneumologia e Tisiologia. Jornal de Pneumologia, v.27, n.6, 2001.

SOUZA, M. V. N.; VASCONCELOS, T. R. A.. Fármacos no combate à tuberculose: passado, presente e futuro. Quím. Nova, v.28, n.4, p.678-682, 2005.

TORTORA, G. J.; FUNKE, B. R.; CASE, C. L.. Microbiologia. 10 ed. Porto Alegre: Artmed, 2012.

VIEIRA, D. E. O.; GOMES, M.. Efeitos adversos no tratamento da tuberculose: experiência em serviço ambulatorial de um hospital-escola na cidade de São Paulo. J. Bras. Pneumol, v.34, n.12, p.1049-1055, 2008.

WHO. World Health Organization. Global tuberculosis report 2015. Geneva: WHO, 2015.

VILLEMIN, J. A.. Cause et nature de la tuberculose. Bull Acad Med, v.37, p.211-216, 1865.

VILLEMIN, J. A.. Etudes sur la tuberculose: preuves rationnelles et experimentales de sa specificite et de son inoculabilite. Paris: J.-B. Bailliere, 1868.

WILDNER, L. M.; NOGUEIRA, C. L.; SOUZA, B. S.; SENNA, S. G.; SILVA, R. M.; BAZZO, M. L.. Microbactérias: Epidemiológicas e Diagnostico. Rev. de Pat. Trop, v.40, n.3, p.207-229; 2011. 